\title{
CAPITAL
}

\section{Pentingnya Produk Hijau dan Gaya Hidup Terhadap Niat Membeli Makanan Organic di Masa Pandemi Covid 19}

\author{
Widi Dewi Ruspitasari \\ Fakultas Ekonomi dan Bisnis, Institut Teknologi dan Bisnis Asia Malang \\ Alamat email: wididewi98@gmail.com
}

\begin{abstract}
The Covid 19 pandemic hit the whole world, especially in Indonesia. This pandemic period requires people to take better care of their health, one of which is by consuming healthy foods that are beneficial to the body. There are several restaurants in Malang that offer healthy food in the form of salads and smoothies. The purpose of this study was to determine the effect of green products and lifestyle on the intention to buy healthy food in the city of Malang. The number of samples in this study were 75 consumers. Quantitative data collected through questionnaires were analyzed using PLS analysis. The results showed that both green products and lifestyle had a great influence on purchase intentions. The strongest factor in green products is the composition of the content, so green products must pay attention to the ingredients in their salads and smoothies. Because the better the vegetables and fruits used, the faster the benefits will be felt by consumers. While the strongest factor that exists in the lifestyle is family interest, where when the family gets used to eating organic food, this will become a habit, which will be carried out continuously and will make it a lifestyle.
\end{abstract}

Keywords: Green Products, Lifestyle, and Purchase Intention

\begin{abstract}
Abstrak
Masa Pandemi Covid 19 melanda seluruh dunia, terutama di Indonesia. Masa pandemic ini mewajibkan masyarakat untuk lebih menjaga Kesehatan salah satunya dengan mengkonsumsi makanan sehat yang bermanfaat bagi tubuh. Ada beberapa restoran di kota Malang yang menawarkan makanan sehat berupa salad dan smoothies. Tujuan dari penelitian ini adalah untuk mengetahui pengaruh produk hijau dan gaya hidup terhadap niat membeli mkanan sehat di kota Malang. Jumlah Sampel dalam penelitian ini sebanyak 75 konsumen. Data kuantitatif yang dikoleksi melalui kuisioner dianalisis menggunakan analisis PLS. Hasil penelitian menunjukkan bahwa baik produk hijau maupun gaya hidup memiliki pengaruh yang besar terhadap niat membeli. Faktor terkuat dalam produk hijau adalah komposisi isi sehingga produk hijau harus memperhatikan kandungan yang ada didalam salad maupun smoothies yang mereka hasilkan. Karena semakin bagus sayur dan buah yang digunakan, akan semakin cepat manfaat yang dirasakan oleh konsumen. Sedangkan faktor terkuat yang ada dalam gaya Hidup adalah minat keluarga, dimana padasaat keluarga terbiasa untuk mengkonsumsi makanan organic, maka hal ini akan menjadi kebiasaa, yang akan dilakukan secara terus menurus dan akan menjadikan sebagai gaya hidup.
\end{abstract}

_Kata Kunci: Produk Hijau, Gaya Hidup, dan Niat Membeli 


\section{A. PENDAHULUAN}

Pandemi Covid 19 yang terjadi di seluruh dunia, khususnya di Indonesia merubah gaya hidup baru di masyarakat. Gaya hidup baru yang berubah di masyarakat salah satunya yaitu dengan mengkonsumsi makanan sehat dan ramah lingkungan. Selain itu masyarakat sudah mulai sadar akan pentingnya menjaga Kesehatan dengan mengkonsumsi makanan sehat, agar terhindar dari penyakit degeneratif yang di akibat gaya hidup tak sehat seperti obesitas, diabetes dan penyakit kardiovaskular.

Menurut Kotler dalam Sabran (2009:210) Gaya hidup merupakan sebuah pola hidup manusia yang terungkap pada aktifitas, minat dan keinginannya. Gaya hidup menggambarkan keseluruhan diri manusia dimana mereka akan berinteraksi dengan lingkungannya. Gaya hidup seseorang bisa berubah seiring dengan seringnya seseorang berinteraksi dengan lingkungannya dan perkembangan teknologi serta ilmu pengetahuan.

Seseorang bisa dengan cepat mengakses internet, sesuai dengat minat dan kebutuhannya. Oleh karena itu masyarakat saat ini lebih mudah untuk mendapatkan informasi tentang kebutuhan Kesehatan sesuai dengan yang diinginkan. Sekitar 80 persen responden Nielsen's New Global Health and Ingredient-Sentiment Survey mengatakan hampir dua pertiga konsumen (64 persen) mengatakan bahwa responden bersedia membayar lebih untuk makanan atau minuman sehat yang tidak mengandung bahan bahan berbahaya. (https://republika.co.id/berita/gayahidup/ infosehat/16/09/06/od39ce335-survei-konsumen-indonesia-lebih-sadarpolamakan-sehat) Konsumen saat ini lebih sadar tentang pentingnya menjaga Kesehatan dengan cara mengatur pola makan. Hal ini merupakan peluang bagi pengusaha untuk menjual produk - produk yang focus terhadap makanan dan minuman organic yang poenting untuk Kesehatan. Karena dengan mengkonsumsi makanan sehat secara otomatis akan mengurangi resiko penyakit yang ditakuti masyarakat salah satunya kanker, auto imun dll.

Selain gaya hidup sehat, masyarakat cenderung lebih sadar tentang pentingnya produk hijau dalam menjaga Kesehatan. Dalam kehidupan sehari-hari masalah tentang lingkungan hidup dan kesehatan menjadi topik utama, pola perilaku masyarakat yang kurang peduli terhadap produk ramah lingkungan seringkali dapat memberikan pengaruh 
baik langsung maupun tidak langsung bagi kesehatan diri sendiri. Tingkat kesadaran masyarakat akan produk organic menjadi factor utama yang harus dipenuhi masyarakat agar masyarakat mendapatkan manfaat saat mengkonsumsi produk hijau(Asnah , 2015). Dalam penelitian Darmadewi (2017) menemukan bahwa faktor-faktor yang mempengaruhi green consumer dalam membeli produk organik terdiri dari 7 faktor yaitu Faktor Keluarga dan Gaya hidup; Faktor Kebiasaan dan pribadi; Faktor kemudahan dan persepsi; Faktor produk dan promosi; Faktor motivasi; Faktor Pelayanan dan harga serta Faktor Teman dan Pendapatan dari dua variabel yaitu teman dan pendapatan. Produk hijau juga sering dikenal dengan produk organik. Standar Nasional Indonesia atau SNI tentang pangan organik (2002) menyatakan bahwa organik adalah istilah pelabelan yang menyatakan bahwa suatu produk telah diproduksi sesuai dengan standar sistem pangan organik dan disertifikasi oleh Lembaga Sertifikasi Organik (LSO) yang telah diakreditasi oleh Komite Akreditasi Nasional (KAN).

Di kota Malang, banyak sekali menjual makanan dan minuman organic. Makanan organic berupa salad yang dikemas dalam bentuk wrap ataupun bowl,sedangkan minuman organic disini yaitu berupa smooties yang diolah menggunakan sayur dan buar organic. Yang dijadikan responden dalam penelitian ini adalah konsumen yang membeli produk greenly dan kecut manis.

\section{B. TINJAUAN PUSTAKA}

Kasali (2015) mendefinisikan produk hijau (green product) adalah barang atau produk yang dibuat oleh produsen yang tidak menimbulkan dampak bagi kesehatan manusia serta aman dikonsumsi. Selain itu, produk hijau juga dihubungkan dengan penggunaan bahan baku yang ramah lingkungan, organic. Produk hijau juga bertujuan untuk mengurangi sampah (waste) dimana kecenderungan karakteristik produk organic adalah mudah untuk terurai. Nugrahadi (2002) menyatakan bahwa produk bersih (green produk) selalu berorientasi pada lingkungan.

Menurut Ottman (2010) produk hijau dapat bertahan dalam waktu yang cukup lama, dikarenakan produk hijau tidak mengandung racun, terbuat dari bahan yang ramah lingkungan dan dapat didaur ulang, Green product yang berupa makan organic, yaitu berasal dari buah ataupun sayuran organic. Organic disini yaitu buah dan sayuran yang tidak menggunakan pestisida, 
D’Souza et al., (2006) menjelaskan bahwa aspek-aspek yang ada di dalam green product atau produk hijau adalah persepsi produk, kemasan, komposisi isi. Persepsi produk dilihat dari produk hijau merupakan suatu produk yang ramah lingkungan dan tidak berbahaya. Kemasan dan komposisi pada produk hijau harus dapat di daur ulang agar meminimalkan kerusakan lingkungan.

Qing et al. (2012), menemukan bahwa gaya hidup berpengaruh positif terhadap pembelian dalam buah segar di China. Menurut Kotler dan Amstrong (2010) gaya hidup dapat dilihat dari perilaku yang berupa kegiatan-kegiatan yang dilakukan seseorang sehingga kegiatan tersebut menjadi kebiasaan yang rutin dilakukan.Menurut Kotler dan Amstrong (2010) yang mempengaruhi gaya hidup seseorang ada 2 faktor yaitu faktor yang berasal dari dalam diri individu (internal) dan faktor yang berasal dari luar (eksternal). Faktor internal salah satunya adalah sikap dimana sikap bisa dipahami sebagai cara seseorang dalam memberikan tanggapan terhadap suatu hal sesuai dengan keadaan jiwa dan pikirannya yang dipengaruhi oleh pengalaman yang pernah dialaminya. Menurut Shah et al (2012) niat untuk membeli adalah sebuah keputusan yang menganalisis serta mempelajari mengapa konsumen membeli sebuah produk di tempat tertentu. Jadi disini pemasar akan mempelajari apa sebab sebab seorang konsumen itu akan memiliki niat membeli untuk suatu produk.

\section{METODE PENELITIAN}

Penelitian ini merupakan field research yang dilakukan dengan menggunakan pendekatan kuantitatif. Populasi dari obyek penelitian ini tidak diketahui jumlahnya secara pasti dikarenakan jumlah konsumen di greenly dan kecut manis tidak dapat terhitung secara pasti. Sehingga pengambilan sampel dilakukan dengan metode accidental sampling dan purposive sampling. Metode accidental sampling dan purposive sampling merupakan bagian dari non-probability sampling yaitu teknik pengambilan sampel dengan cara menemukan konsumen yang membeli produk greenly dan kecut manis yang ditemui secara langsung dan tidak sengaja, kemudian konsumen diberi kuisioner dan responden tersebut memiliki kriteria yang menjadi pertimbangan peneliti, yaitu: (1) bersedia menjadi responden, (2) minimal telah 1x (satu kali) membeli produk greenly ataupun kecut manis dan (3) membeli produk greenly dan kecut manis untuk dikonsumsi sendiri, bukan membelikan orang lain. 
Jumlah sampel yang diambil dalam penelitian ini adalah 75 responden. Ini sesuai dengan perhitungan Wibisono dalam Akdon (2013) untuk jumlah populasi yang tidak diketahui. Data yang terkumpul akhirnya dianalisis menggunakan analisis Parsial Least Square (PLS) agar mencapai analisis yang lebih mendalam yaitu sampai pada tataran indicator.

Tabel 1. Indikator dan Item Setiap Variabel Penelitian

\begin{tabular}{|l|l|l|}
\hline \multicolumn{1}{|c|}{ Variabel } & \multicolumn{1}{|c|}{ Indikator } & \multicolumn{1}{c|}{ Item } \\
\hline Produk Hijau (X1) & Kemasan & Kemasan dapat didaur ulang \\
\cline { 2 - 3 } & Komposisi isi & Bahan organik \\
\hline Gaya Hidup (Y1) & Aktifitas bekerja & $\begin{array}{l}\text { Keinginan hidup sehat karena } \\
\text { sibuk }\end{array}$ \\
\cline { 2 - 3 } & Minat keluarga & $\begin{array}{l}\text { Keluarga terbiasa makan } \\
\text { makanan sehat }\end{array}$ \\
\cline { 2 - 3 } & Opini Ekonomi & $\begin{array}{l}\text { Ada anggaran untuk membeli } \\
\text { makanan sehat }\end{array}$ \\
\hline \multirow{5}{*}{ Niat Membeli (Y2) } & $\begin{array}{l}\text { Mempertimbangkan } \\
\text { membeli }\end{array}$ & $\begin{array}{l}\text { Mempertimbangkan } \\
\text { membeli }\end{array}$ \\
\cline { 2 - 3 } & Tertarik untuk mencoba & Tertarik ingin mencoba rasanya \\
\cline { 2 - 3 } & Ingin mengetahui produk & $\begin{array}{l}\text { Ingin mengetahui varian yang } \\
\text { ditawarkan }\end{array}$ \\
\cline { 2 - 3 } & Ingin mengkonsumsi produk & Ingin mengkonsumsi \\
\hline
\end{tabular}

\section{HASIL DAN PEMBAHASAN}

Berdasarkan data responden menunjukkan karakteristik responden penelitian didominasi oleh laki - laki yaitu dengan persentase 67,40\%. Dengan usia mayoritas berumur $<30$ tahun yaitu sebesar 75\%. Dan pendidikan mayoritas sarjana (S1) sebesar $54,75 \%$.

Berdasarkan hasil tanggapan responden mengenai variabel produk hijau sesuai dengan komposisi yaiyu menggunakan sayur dan buah organic tanpa menggunkana pestisida. Hal ini terlihat dari mean variabel produk hijau yang tergolong sedang yaitu 3.92 yang dapat dikategorikan baik. Sehingga dapat dimaknai bahwa produk hijau mendorong setiap konsumen di greenly dan kecut manis berfikiran bahwa pemilihan makanan sehat sangat diperlukan bukan saja pada kondisi sekarang ini namun untuk menjaga kesehatan dimasa yang akan datang. 
Hasil tanggapan responden pada variabel gaya hidup juga dinilai sedang oleh konsumen dengan mean variabel 3.36. Hal ini menunjukkan bahwa konsumen greenly dan kecut manis rela untuk membayar makanan walaupun sedikit mahal demi kesehatan.

Hasil jawaban responden untuk variabel niat untuk membeli juga dinilai sedang oleh konsumen greenly dan kecut manis yaitu sebesar 3.97. Hal ini menunjukkan bahwa konsumen atau pelanggan pada rumah makan sehadi geenly dan kecut manis tertarik untuk mencoba.

Pengujian validitas dan reliabilitas untuk ketiga variabel dikatakan valid dan reliabel apabila Indikator memiliki nilai korelasi diatas 0,70. Namun demikian pada penelitian tahap pengembangan skala loading 0,50 sampai 0,60 masih dapat diterima. Begitu pula untuk reliabilitas, Indikator dinyatakan reliabel jika nilai composite reliability maupun cronbach alpha diatas 0.70 (Ghozali, 2008).

Indikator dalam variabel pruduk hijau diukur dengan menggunakan 2 indikator yang besarnya nilai korelasi dalam pengujian validitas menunjukkan angka $>0,50$ dan untuk pengujian reliabilitas menunjukkan angka $>0,70$, sehingga seluruh indikator pada variabel produk hijau menunjukkan valid dan reliabel. Begitu pula dengan variabel Gaya Hidup yang diukur dengan 3 indikator memiliki nilai korelasi dalam pengujian validitas menunjukkan angka> 0,50 dan untuk pengujian reliabilitas menunjukkan angka >0,70, kemduian variable niat membeli yang diukur dengan menggunakan 4 indikator memiliki nilai korelasi dalam pengujian validitas menunjukkan angka $>0,50$ dan untuk pengujian reliabilitas menunjukkan angka >0,70, berikut table hasil uji validitas dan reabulitas

Tabel 2. Hasil Uji Validitas Dan Reliabilitas Instrumen Variabel Health involvement, Green consumer, dan Intention to purchase.

\begin{tabular}{|c|c|c|c|c|c|c|}
\hline $\begin{array}{l}\text { Variabel/ } \\
\text { Indikator }\end{array}$ & $\begin{array}{c}\text { Item } \\
\text { (Butir) }\end{array}$ & $\begin{array}{c}\text { Koefisien } \\
\text { Korelasi (r) }\end{array}$ & Sig. & Ket. & $\begin{array}{c}\text { Cronbach's } \\
\text { Alpha }\end{array}$ & Ket. \\
\hline Produk hijau $\left(\mathrm{X}_{1}\right)$ & $\begin{array}{l}\mathrm{X}_{1.1} \\
\mathrm{X}_{1.2}\end{array}$ & $\begin{array}{c}0.857 \\
0.83\end{array}$ & $\begin{array}{l}0,000 \\
0,000\end{array}$ & Valid & 0.736 & Reliabel \\
\hline Gaya Hidup ( $\left.\mathrm{Y}_{1}\right)$ & $\begin{array}{l}\mathrm{Y}_{1.1} \\
\mathrm{Y}_{1.2} \\
\mathrm{Y}_{1.3} \\
\end{array}$ & $\begin{array}{l}0.798 \\
0.871 \\
0.821 \\
\end{array}$ & $\begin{array}{l}0,000 \\
0,000 \\
0,000\end{array}$ & Valid & 0.842 & Reliabel \\
\hline $\begin{array}{l}\text { Intention to } \\
\text { purchase }\left(\mathrm{Y}_{2}\right)\end{array}$ & $\begin{array}{l}\mathrm{Y}_{2.1} \\
\mathrm{Y}_{2.2} \\
\mathrm{Y}_{2.3} \\
\mathrm{Y}_{2.4}\end{array}$ & $\begin{array}{l}0.836 \\
0.828 \\
0.786 \\
0.875\end{array}$ & $\begin{array}{l}0,000 \\
0,000 \\
0,000 \\
0,000\end{array}$ & Valid & 0.903 & Reliabel \\
\hline
\end{tabular}

Sumber: Diolah Penulis (2021) 
Berdasarkan table di atas menunjukkan nilai validitas dan reabilitas yang tinggi, sehingga dapat penelitian ini dapat dilanjutkan ketahap selanjutnya.

Berdasarkan hasil pengujian model dengan uji goodness - fit model dengan bantuan software Smart PLS, sebagai berikut :

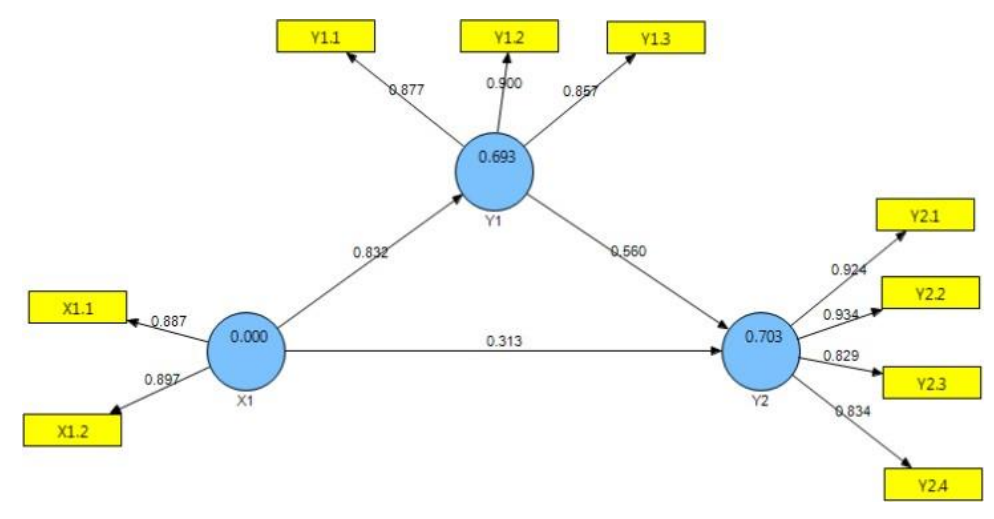

Gambar 1. Pengujian Model (Measurement Model)

Hasil analisis pada Gambar 1 dapat dijelaskan hasil outer loading semua indikator berbentuk reflektif tidak ada yang memiliki loading kurang dari 0,50 (OL<0,50), sehingga model tidak perlu dilakukan reestimasi kembali dengan menghilangkan indikator.

Gambar 1 diperoleh juga nilai $\mathrm{R}$ - Square yang dapat di lihat pada table berikut:

Table 3. R - Square

\begin{tabular}{cc}
\hline & R - Square \\
\hline Produk Hijau $\left(\mathrm{X}_{1}\right)$ & \\
\hline Gaya HIdup $\left(\mathrm{Y}_{1}\right)$ & 0,693 \\
\hline Intention to purchase $\left(\mathrm{Y}_{2}\right)$ & 0,703 \\
\hline
\end{tabular}

Sumber: Diolah Penulis (2021)

Berdasarkan hasil perhitungan pada Tabel 3, pengujian kelayakan model digunakan koefisien determinasi total $\left(\mathrm{Q}^{2}\right)$, Q-Square mengukur seberapa baik nilai observasi yang dihasilkan oleh model dan juga estimasi parameternya (Ghozali, 2006). Nilai Q-square lebih besar daripada nol (0) menunjukan bahwa model mempunyai nilai 
memiliki predictive relevance, sedangkan Q-square kurang dari nol (0) menunjukan bahwa model kurang memiliki predictive relevance. Untuk menentukan nilai Q-square digunakan formula sebagai berikut:

$$
Q^{2}=1-\left(1-\mathrm{R}_{1}^{2}\right) *\left(1-\mathrm{R}_{2}^{2}\right)
$$

Perhitungan Q-square dengan menggunakan data R-square yang ada pada tiga model di atas dapat dilakukan sebagai berikut:

$$
\begin{aligned}
& Q^{2}=1-(1-0,693) *(1-0,703) \\
& Q^{2}=\mathbf{0 , 9 0 9}
\end{aligned}
$$

Berdasarkan perhitungan Q-square $\left(\mathrm{Q}^{2}\right)$ diperoleh nilai Q-square sebesar 0,909 angka tersebut dapat diinterpretasikan bahwa model penelitian dapat menjelaskan 90,90\%. Artinya besarnya pengaruh variabel Produk hijau terhadap Gaya Hidup, dan Intention to purchase sebesar 90,90\%, sedangkan 9,10\% dipengarahui factor lain yang juga berpengaruh terhadap Intention to purchase, sehingga model yang telah dibangun mempunyai nilai predictive relevance atau tingkat prediksi yang cukup akurat.

Berdasarkan hasil pengujian dengan uji t (uji hipotesis) dengan bantuan software

\begin{tabular}{|c|c|c|c|c|}
\hline & $\begin{array}{c}\text { Original } \\
\text { Sample }(\mathrm{O})\end{array}$ & $\begin{array}{l}\text { T Statistics } \\
(|\mathrm{O} / \mathrm{STERR}|)\end{array}$ & P-Value & Ket. \\
\hline $\begin{array}{c}\text { Produk Hijau }\left(\mathrm{X}_{1}\right) \text {-> Gaya } \\
\text { HIdup (Y1) }\end{array}$ & 0.832 & 24.778 & 0.000 & Signifikan \\
\hline $\begin{array}{c}\text { Produk Hijau }\left(\mathrm{X}_{1}\right)->\text { Intention } \\
\text { to purchase }(\mathrm{Y} 2)\end{array}$ & 0.313 & 2.742 & 0.006 & Signifikan \\
\hline $\begin{array}{c}\text { Gaya Hidup }\left(\mathrm{Y}_{1}\right)->\text { Intention to } \\
\text { purchase }(\mathrm{Y} 2)\end{array}$ & 0.560 & 5.484 & 0.000 & Signifikan \\
\hline
\end{tabular}
Smart PLS, diperoleh hasil pengaruh antar variabel sebagai berikut:

Table 4. Hasil Pengaruh Antar Variabel

Sumber: Diolah Penulis (2021)

Hasil koefisien estimate untuk pengaruh Produkm Hijau dengan Gaya Hidup menunjukkan nilai koefisien estimate sebesar 0.832. koefisien tersebut bertanda positif yang apabila semakin baik Product hijau maka Gaya Hidup meningkat pula. Dan nilai statistik sebesar 24,778 yang menunjukkan bahwa adanya pengaruh yang signifikan variabel product hijau terhadap Gaya HIdup, hal ini dapat lihat pada nilai P-Value sebesar 0,000 atau T Statistik lebih besar dari1,96. 
Berdasarkan tabel 4 juga menjelaskan untuk pengaruh product hijau dengan Intention to purchase menunjukkan nilai koefisen estimate sebesar 0.313 yang berarti adanya pengaruh positif antara produk hijau dengan Intention to purchase. Dan nilai statistik sebesar 2,742 yang menunjukkan bahwa adanya pengaruh yang signifikan variabel produk hijau terhadap Intention to purchase, hal ini didapat lihat pada nilai PValue sebesar 0,000 atau T Statistik lebih besar dari1,96.

Besarnya nilai koefisien estimate dari gaya hidup terhadap Intention to purchase adalah 0.560 . koefisien tersebut bertanda positif yang apabila gaya hidup meningkat maka Intention to purchase pun juga meningkat, begitu pula sebaliknya. Sedangkan nilai T Statistik sebesar 5.484 atau lebih besar dari1,96, selain itu dapat dilihat pada nilai P-Value sebesar 0,000 .

Berdasarkan pada table 4 dapat diketahui bahwa besarnya koefisien pengaruh langsung Produk Hijau terhadap Intention to purchase lebih besar dari pengaruh tidak langsung Produk hijau terhadap Intention to purchase sebagai berikut.

Table 5. Pengaruh Tidak Langsung

\begin{tabular}{cc}
\hline Pengaruh & Koefisien Pengaruh \\
\hline Produk Hijau (X1) -> Intention to purchase \\
$\begin{array}{c}\text { (Y2) } \\
\text { Produk Hijau (X1) -> Gaqya Hidup (Y1) -> } \\
\text { Intention to purchase (Y2) }\end{array}$ \\
$\begin{array}{c}\text { Sumber: Diolah Penulis (2021) }\end{array}$
\end{tabular}

Tabel 5 dapat diketahui bahwa besarnya koefisien pengaruh langsung Produk Hijau terhadap Intention to purchase lebih kecil dari pengaruh tidak langsung Produk Hijau terhadap Intention to purchase, yang berarti bahwa variable Gaya Hidup merupakan variable mediasi atau variable intervening yang berperan memediasi antara variable Produk Hijau terhadap Intention to purchase melalui variable Gaya Hidup, namun jika dilihat dari sifat mediasinya adalah mediasi sebagian (Partial mediation), dikarenakan peran mediasi tidak sepenuhnya. 


\section{E. SIMPULAN}

Berdasarkan hasil penelitian dan pembahasan dapat disimpulkan bahwa: Produk Hijau berpengaruh positif dan signifikan terhadap Gaya Hidup, yang berarti bahwa produk hijau yang terdiri kemasan dan komposisi isi dapat mempengaruhi Gaya Hidup. Dikarenakan pada saat konsumen dapat merasakan manfaat mengkonsumsi makanan sehat akan menjadi kebiasaan, apalagi pada masa pandemic saat ini, dimana sangat dibutuhkan asupan dan vitamin untuk meningkatkan imunitas tubuh. Sesuai dengan penelitian Randra 2014 yang menemukan bahwa Produk hijau mempengaruhi niat mempeli produk di Carefful

Selanjutnya Gaya Hidup berpengaruh positif dan signifikan terhadap Intention to purchase, Gaya Hidup yang terdiri dari aktifitas bekerja, minat keluarga dan opini ekonomi dapat meningkatkan Intention to purchase. Menurut Parubak (2010), gaya hidup merupakan sebuah gambaran seseorang didalam memilih apa yang dikehendakinya. Pada saat gaya hidup seseorang sudah mulairutin mengkonsumi makanan sehat produk greenly atau kecut manis maka konsumen akan selalu memiliki niat membeli diakrena sudah dapat merasakan pentingnya mengkonsumsi makan organic.

Dimana fenomena ini akan membentuk pola pikir seseorang kemudian pengaruh langsung Produk Hijau terhadap Intention to purchase memiliki pengaruh positif dan signifikan, yang artinya bahwa peningkatan Produk Hijau akan berdampak pada peningkatan Intention to purchase. Selanjutnya peran mediasi Gaya Hidup antara Produk Hijau terhadap Intention to purchase memiliki peran sebagai mediasi partial, maknya bahwa peningkatan Produk Hijau akan berdampak pada peningkatan Intention to purchase yang dipicu oleh peningkatan dari Gaya Hidup.

\section{DAFTAR PUSTAKA}

A. Balawera. (2013). Green Marketing and Corporate Responsibility Pengaruhnya Terhadap Keputusan Pembelian. Jurnal EMBA, 1(4), 2117-2129

Akdon, dan Riduwan. (2013). Rumus dan Data Dalam Analisis Statistika. Alfabeta, Bandung. 
Asnah, Heriyanto,Dina Meillita. 2017. Analsis Persepsi Masyarakat Terhadap Keputusan Pembelian Produk Sayur Organik di Kota Palembang. Fakultas Ekonomi dan Bisnis Universitas Bina Darma Palembang

Atmaja, N. P. C. D., \& Utami, N. M. S. (2017). Faktor-faktor yang Mempengaruhi Green Consumer dalam Membeli Produk Organik. Prosiding Seminar Nasional Hasil Penelitian, 30 September 2017, 127-146.

Kotler, P. (2012). Marketing management/Philip Kotler, Kevin Lane Keller. Pearson Education International.

Kasali, R. 2015. Membidik Pasar Indonesia, Segmenting, Targeting, Positioning. Gramedia Pustaka Utama Jakarta:

Nugrahadi, E. W. 2002. Pertanian Organik Sebagai Alternatif Teknologi dalam Upaya Menghasilkan Produk Hijau. Jurnal bisnis dan manajemen Vol.2.No.1,2006

Ottman, J. A. (2010). The Five Simple Rules of Green Marketing. Design Management Review, 19(4), 65-69. https://doi.org/10.1111/j.1948-7169.2008.tb00143.x

Qing, Lobo, Antonio and Chongguang, Li. 2012.The Impact of Lifestyle and Ethnocentrism on Consumers Purchase Intention of Fresh Fruit in China. Faculty of Economics and Management, Huazhong Agricultural University, Wuhan, People's Republic of China.

Shah, S.S. Hussain, J. Aziz, A.R. Jaffari, S.Waris, W.Ejaz, M.Fatima and S.K. Sherazi. 2012. The Impact of Brands on Consumer Purchase Intentions. Asian Journal of Bussiness Management. Vol.4, No.2, pp: 105-110.

Suraputra, I. M. W., \& Warmika, I. G. K. (2017). Fakultas Ekonomi dan Bisnis Universitas Udayana, Bali, Indonesia Perkembangan industri otomotif di Indonesia sangat cepat dan cendrung meningkat setiap tahunnya, seiring dengan kebutuhan dan permintaan masyarakat akan sarana transportasi yang memadai ,. 6(1), 176-203. 